\title{
Clinical Characteristics and Angiographic Profile of Acute Coronary Syndrome Patients in a Tertiary Hospital of Bangladesh
}

\author{
Mohsin Ahmed ${ }^{1}$, Khandaker Abu Rubaiyat ${ }^{2}$, Mohammed Abaye Deen Saleh ${ }^{3}$, Abdul Wadud Chowdhury ${ }^{4}$, \\ C. M Khudrate-E-Khuda ${ }^{5}$, Kazi Abul Fazal Ferdous ${ }^{6}$, Nahid Hasan ${ }^{7}$, Abu Taher Mohammad Mahfuzul Hoque ${ }^{8}$, \\ Kazi Nazrul Islam ${ }^{5}$, Md. Gaffar Amin ${ }^{8}$
}

\begin{abstract}
Aims: Coronary artery disease is a devastating disease precisely because an otherwise healthy person in the prime of life may die or become disabled without warning. The objectives were to study the clinical profile, risk factors prevalence, angiographic distribution and severity of coronary artery stenosis in acute coronary syndrome (ACS) patients admitted in Cardiology Department of Dhaka Medical College Hospital, Dhaka. Materials and Methods: A total of $\mathbf{8 0 0}$ patients of ACS were analyzed for various risk factors, angiographic patterns and severity of coronary artery disease at DMCH, Dhaka, Bangladesh. Results: Mean age of presentation was $51.27 \pm 8.80$ years. Majority were male $628(78.5 \%)$ and rest were females $(21.5 \%)$. Most
\end{abstract}

patients had ST elevated myocardial infarction (STEMI) 509 (63.6\%) followed by non-STEMI (NSTEMI) 207 (25.9\%) and Unstable Angina (UA) 84 (10.5\%). Risk factors: smoking was present in $388(48.5 \%)$, hypertension in $289(36.13 \%)$, diabetes in $235(29.38 \%)$, dyslipidaemia in $169(21.13 \%)$ and obesity in $356(44.5 \%)$ patients. Singlevessel disease was present in $30.32 \%$ patients, Doublevessel disease was present in $\mathbf{2 3 . 2 3 \%}$ patients and Triple vessel disease was present in $27.15 \%$ patients. Conclusion: STEMI was the most common presentation. ACS occurred earlier in comparison to Western population. Smoking was most prevalent risk factor. Diabetic patients had more multivessel disease.

Key words: Acute Coronary Syndrome, Angiogram, Bangladesh.
Introduction:

Coronary artery disease is a global health problem reaching an epidemic in both developed and developing countries

1. Associate Professor, Department of Cardiology, Dhaka Medical College, Dhaka, Bangladesh.

2. MD, Final Part Student, Dhaka Medical College, Dhaka, Bangladesh.

3. Junior Consultant (Cardiology), District Hospital, Gaibandha, Bangladesh

4. Professor, Department of Cardiology, Dhaka Medical College, Dhaka, Bangladesh.

5. Junior Consultant (Cardiology), Dhaka Medical College, Dhaka, Bangladesh

6. Indoor Medical Officer (Cardiology), Dhaka Medical College Hospital, Dhaka, Bangladesh.

7. D Card Student, Dhaka Medical College, Dhaka, Bangladesh.

8. Assistant Professor, Department of Cardiology, Dhaka Medical College, Dhaka, Bangladesh.

Address of Correspondence: Dr. Mohsin Ahmed, Associate Professor, Dept. of Cardiology, Dhaka Medical College Hospital, Dhaka, Bangladesh. Mobile: +88 01613393186, Email: mohsinsohel07@gmail.com and is the leading cause of mortality and morbidity worldwide ${ }^{1,2}$. In 1990 coronary artery disease accounted for $28 \%$ of world's 50.4 million deaths and $9.7 \%$ of the 1.4 billion lost disability adjusted life years. By 2020 the world's population will grow to 7.8 billion and $32 \%$ of all deaths will be caused by coronary artery ${ }^{3}$. The South Asian countries have among the highest incidence of coronary artery disease globally ${ }^{4}$. Estimates from the global burden of disease study suggests that by the year 2020, this part of the world will have more individuals with atherosclerotic coronary artery disease than in any other region ${ }^{4,5}$. Data related to different aspects of CAD in Bangladesh are inadequate but it is highly prevalent in Bangladesh ${ }^{6}$. While the death rates related to CAD have been declining for the past three decades in the west, these rates are rising in

DOI: http://dx.doi.org/10.3329/bhj.v33i1.37018

Copyright () 2017 Bangladesh Cardiac Society. Published by Bangladesh Cardiac Society. This is an Open Access articles published under the Creative Commons Attribution-NonCommercial 4.0 International License (CC BY-NC). This license permits use, distribution and reproduction in any medium, provided the original work is properly cited and is not used for commercial purposes. 
Bangladesh. In the last three decades, the prevalence of CAD has increased from $1.1 \%$ to about $7.5 \%$ in urban population of Delhi, India and from $2.1 \%$ to $3.7 \%$ in the rural population ${ }^{7}$. In Asian Indians, CAD tends to occur at a younger age with more extensive angiographic involvement ${ }^{8}$ contributed by genetic, metabolic, conventional and nonconventional risk factors ${ }^{9,10}$. The objectives of this retrospective study were to study the clinical profile, prevalence of risk factors and distribution of coronary artery stenosis in acute coronary syndrome (ACS) patients admitted in Cardiology Department of Dhaka Medical College Hospital, Dhaka.

\section{Materials and Methods:}

Eight hundred patients presented to Cardiology Department of Dhaka Medical College Hospital with first episode of ACS were analyzed. The clinical presentations of patient were categorized as unstable angina (UA), non-ST elevated myocardial infarction (NSTEMI) and STEMI according to American College of Cardiology/American HeartAssociation (ACC/AHA) definitions and treated as per ACC/AHA recommendations ${ }^{11,12}$. Patients with concomitant valvular heart disease or cardiomyopathy were excluded from this study.

The following data were included for analysis: Age, gender, CAD risk factor profile, current cigarette/ bidi smoking history; dyslipidemia defined as the presence of any of the following: patients on lipid lowering drugs or total cholesterol $>240$ $\mathrm{mg} / \mathrm{dl}$, triglycerides (TG) $>150 \mathrm{mg} / \mathrm{dl}$, low-density lipoprotein $>130 \mathrm{mg} / \mathrm{dl}$, and high-density lipoproteins (HDL) $<50 \mathrm{mg} / \mathrm{dl}$ for female and $<40 \mathrm{mg} / \mathrm{dl}$ for male; diabetes mellitus with symptoms of diabetes and plasma glucose concentration e"200 mg/dl ( $11.1 \mathrm{mmol} / \mathrm{L})$ or fasting blood sugar e" $126 \mathrm{mg} /$ dl $(7.0 \mathrm{mmol} / \mathrm{L})$ or 2-hours post-prandial glucose e" $200 \mathrm{mg} /$ dl $(11.1 \mathrm{mmol} / \mathrm{L})$; hypertension (systolic blood pressure e"140 and/or diastolic e"90 mmHg and/or on anti hypertensive treatment); family history of CAD (first degree relatives before the age of 55 years in men and 65 years in women); obesity defined using the body mass index (BMI) with a value $>25$.

Clinical manifestations, left ventricular ejection fraction, hematologic indices, coronary angiographic findings and treatment strategy were reported. Selective coronary angiogram was done using standard technique. Expert opinion on coronary angiography was taken by two cardiologists. Significant CAD was defined as a diameter stenosis $>70 \%$ in each major epicardial artery. Normal vessels were defined as the complete absence of any disease in the left main coronary artery (LMCA), left anterior descending (LAD), right coronary artery (RCA), and left circumflex (LCX) as well as in their main branches (diagonal, obtuse marginal, ramus intermedius, posterior descending artery, and posterolateral branch). Patients were classified as having single-vessel disease (SVD), double-vessel disease (DVD) or triple vessel disease (TVD) accordingly.

\section{Statistical analysis}

The results were reported as mean \pm standard deviation for the quantitative variables and percentages for the categorical variables. The groups were compared using the Student's $t$-test for the continuous variables and the Chi-square test for the dichotomous variables. $P<0.05$ were considered as statistically significant. All the statistical analyses were carried out via Statistical Package for Social Sciences version 20 (SPSS, IL, Chicago Inc., USA).

\section{Results:}

Among 800 ACS patients majority were male 628 (78.5\%) and $172(21.5 \%)$ were female. The mean age of presentation was $51.27 \pm 8.80$ years. Most common presentation in ACS was STEMI with 509 (63.6\%) patients followed by NSTEMI $207(25.9 \%)$ and UA 84 (10.5\%). Baseline characteristics are mentioned in Table 1.

Table-I

Baseline characteristics of the study population $(N=800)$

\begin{tabular}{lccc}
\hline Variables & Minimum & Maximum & Mean \\
\hline Age & 16 & 88 & 51.27 \\
Waist Circumference & 45 & 172 & 90.36 \\
Hip Circumference & 40 & 185 & 106.82 \\
FBS (mmol/l) & 2.1 & 21 & 7.12 \\
HbA1C & 4.8 & 14 & 6.74 \\
Total Cholesterol (mg/dl) (\%) & 78 & 400 & 177.69 \\
LDL (mg/dl) & 56 & 270 & 112.99 \\
HDL (mg/dl) & 18 & 71 & 37.40 \\
TG (mg/dl) & 83 & 1125 & 190.49 \\
S creatinine (mg/dl) & 0.38 & 2.30 & 1.60 \\
ESR (mm in 1st hour) & 7 & 85 & 26.55 \\
Echocardiography (\%) & 22 & 78 & 53.29 \\
\hline
\end{tabular}

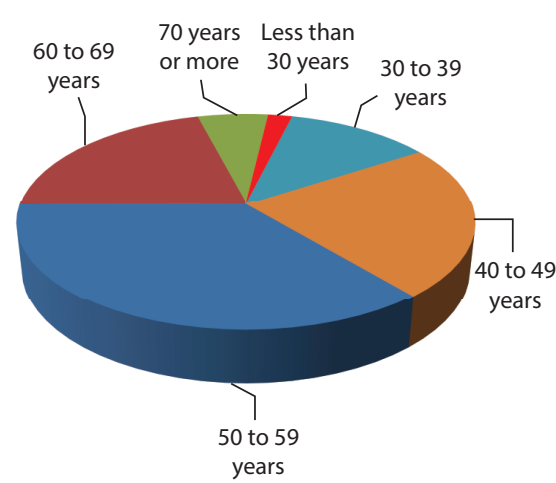

Fig.-1: Age distribution of the study population $(N=800)$ 


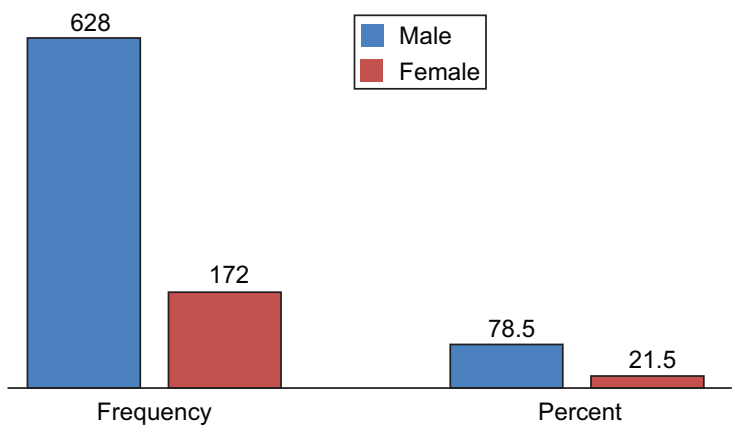

Fig.-2: Distribution of study population according to sex $(N=800)$

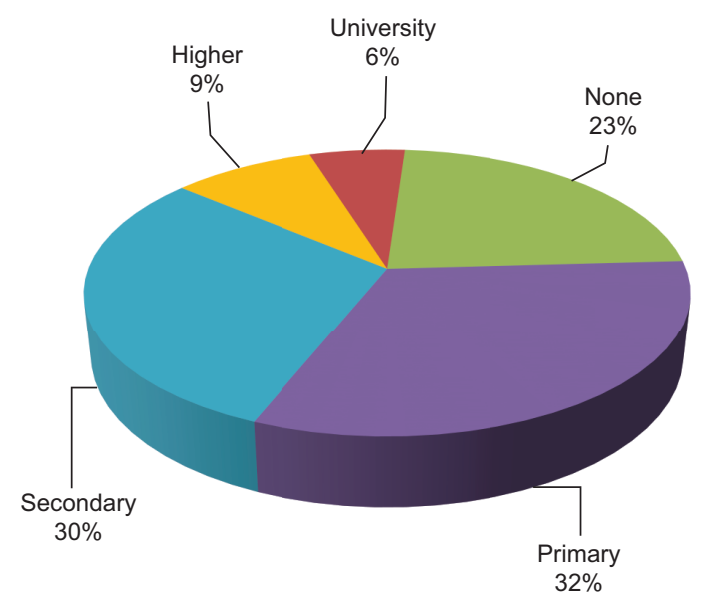

Fig.-3: Distribution of study population according to educational status

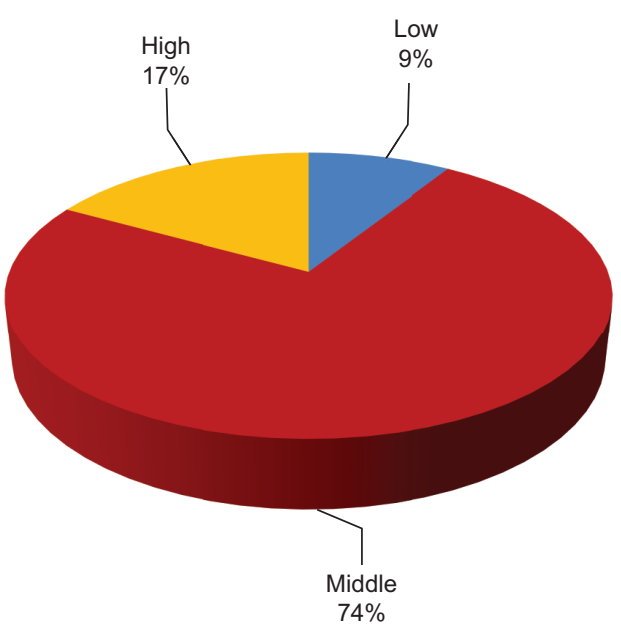

Fig.-4: Distribution of study population according to level of income $(N=800)$

\section{Risk factors analysis}

A total of $235 / 800$ (29.38\%) patients were diabetic and $289 / 800$ (36.13\%) patients were hypertensive. Smoking and tobacco users were $388 / 800$ (48.50\%) patients. Active smoking in our study was noticed only in male patients. Women were rather betel nut/tobacco leaf chewers. Dyslipidemia was present in 169/800 (21.13\%) patients. Obesity in 356/800 (44.5\%) patients and family history of CAD was significant in $25 / 800$ (3.13\%) patients. (Table 2)

Table-II

Distribution of study population according to clinical risk factors

\begin{tabular}{lcc}
\hline Clinical Risk Factor & Frequency & Percent \\
\hline Ischemic Heart Disease & 255 & 31.85 \\
Family History of CAD & 25 & 3.13 \\
Obesity & 356 & 44.5 \\
Diabetes & 235 & 29.38 \\
Hypertension & 289 & 36.13 \\
Previous PTCA & 21 & 2.62 \\
Smoking \& tobacco use & 388 & 48.5 \\
Previous CABG & 12 & 1.54 \\
OCP & 36 & 4.46 \\
Dyslipidemia & 169 & 21.13 \\
Menopause & 32 & 4.00 \\
Alcohol & 5 & 0.62 \\
\hline
\end{tabular}

\section{Angiographic profile}

SVD was seen in $30.32 \%$ patients, DVD in $23.23 \%$ patients, TVD in $27.15 \%$ patients, normal coronary vessels in $17.19 \%$ and nonsignificant lesion were seen in $2.11 \%$ patients out of 800 patients.

Table-III

Distribution of study population according to extent of disease

\begin{tabular}{lcc}
\hline Extent of Disease & Frequency & Percent \\
\hline Single Vessel & 243 & 30.32 \\
Double Vessel & 186 & 23.23 \\
Triple Vessel & 217 & 27.15 \\
Normal Coronaries & 137 & 17.19 \\
Insignificant CAD & 17 & 2.11 \\
\hline
\end{tabular}




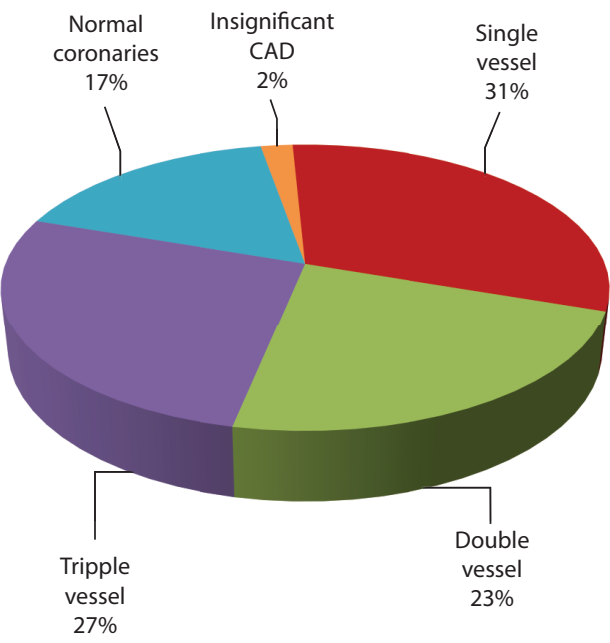

Fig.-5: Distribution of study population according to extent of disease

\section{Discussion:}

Epidemiological studies have revealed that the prevalence of CAD is increasing along with the rising prevalence of conventional risk factors for CAD in Bangladesh ${ }^{31}$. Present health transition from predominance of infections to the preponderance of cardiovascular disorders, such as hypertension, diabetes and CAD is now responsible for $53 \%$ of all deaths ${ }^{10,13}$. At present developing countries contribute a greater share to the global burden of cardiovascular disease than developed countries ${ }^{14}$. The disease is very common in westernized population affecting the majority of adults over the age of 60 years. It is also rising in developing countries. This retrospective study was carried out at the Department of Cardiology, DMCH, Dhaka during the period of January 2016 and December 2017. Coronary artery disease tends to be more aggressive and manifests at a younger age ${ }^{15}$. The mean age of the study population was $51.27 \pm 8.80$ years as compared to $52 \pm 10.8$ years in a study reported by Maqbool Jafary et al ${ }^{16}$ and $58 \pm 11$ years by Sahed et $\mathrm{al}^{17}$ in Pakistan and $62 \pm 5$ years in COURAGE trial ${ }^{18}$ conducted in USA. It is also similar to the study done by Islam AEMM et al ${ }^{19}$ where the mean age in male was $51 \pm 9.8$ and female 47.2 \pm 9.67 . This signifies that Bangladeshi patients are relatively younger as compared to the western people. The skewed gender distribution (males $78.5 \%$ versus females $21.5 \%$ ) of the study population can be attributed to the gender bias and atypical presentation, which is also a feature in INTERHEART study and its South Asian cohort (overall male, $76 \%$ and South Asian cohort, $85 \%$ ) $^{20}$. The study showed that the prevalence of diabetics was $29.38 \%$, which is higher than the reported prevalence in INTERHEART study but near to other Indian studies
(CREATE, Jose and Gupta) ${ }^{10,21}$. Diabetes mellitus alone was a risk factor in $7.13 \%$ patient and combined with hypertension and diabetes mellitus were been in $22.25 \%$ patients. Diabetes mellitus is well known to have an adverse influence on the prognosis of patients with acute myocardial infarction ${ }^{22}$. Majority of the patients suffered from TVD $(40.66 \%)$ which was also higher in Akanda et al ${ }^{23}(42.11 \%)$ conducted in Bangladesh. Hypertension is another conventional risk factor implicated in CAD. In this study $36.13 \%$ patients were hypertensive. The prevalence of hypertension in South Asian cohort of INTERHEART study ${ }^{16}$ (31.1\%) is comparatively lower than this study but is similar to Akanda et $\mathrm{al}^{23}(35 \%)$. The higher prevalence of diabetes and hypertension in this region could be explained by the comparatively higher development and increasing epidemic of $C A D^{24}$. Tobacco smoking is a known modifiable risk factor for CAD. In our study, 388 (48.5\%) patients were smoker or tobacco leaf/betel nut chewers. All reported data show that smoking is the commonest risk factor encountered in patients with acute myocardial infarction ${ }^{25,26}$. The male preponderance and smoking being the major risk factors has been well documented in many studies in this subcontinent $27,28,29,30$. However in contrast to this study, smoking is not a major risk factor in the COURAGE trial ( $29 \%$ vs $60 \%)$. The prevalence of obese patients was only $44.5 \%$ which is less than the prevalence seen in South Asian cohort of INTERHEART study (44.2\%). Single-vessel involvement was $30.32 \%$ in all groups of ACS including UA, NSTEMI and STEMI, followed by triple-vessel $(27.15 \%)$ and double vessel disease (23.23\%). Akanda et al ${ }^{23}$ also showed more single vessel involvement. Angiographically, the absolutely normal vessels were present in $14.25 \%$ cases have been attributed to complete recanalization whether spontaneously or post-thrombolysis. The study limitations include the noninclusion of factors like detailed dietary habits, exercise frequency and substance abuse.

\section{Conclusion:}

CAD is highly prevalent in Bangladesh, as well as is a major health challenge for us. Despite decrease in cardiovascular disease mortality in developed countries, substantial increases have been experienced in developing countries like ours. Along with the classical risk factors, genetic makeup and environmental factors unique to our population may contribute. The rapid changes in lifestyle, unhealthy habits (smoking, sedentary life style etc.), dietary factors, economic development and higher prevalence of diabetes and hypertension are considered to be responsible for the increase of mortality. Overall, SVD was most prevalent in ACS patients. Diabetic patients had more multi-vessel disease than non-diabetics. Hence large-scale, preferably, 
nation-wide survey and clinical research should be conducted to determine the different aspects of CAD in Bangladesh as well as to identify the magnitude of problem and timely primary and secondary prevention strategies should be vigorously pursued.

\section{References:}

1. Islam SMS, Purnat TD, Phuong NTA, Mwingira U, Schacht K, Fröschl G. Non Communicable Diseases (NCDs) in developing countries: a symposium report. Global Health 2014;10(01):81.

2. Murray CJ, LopezAD. Measuring the global burden of disease. N Engl J Med 2013;369(5);448-59.

3. Gazanio TA, Gazanio JM. Global burden of cardiovascular disease 'In: RO. Bonow, DL. Mann, DPZipes, P. Libby, 9th ed. Braunwald Heart disease: A text book of cardiovascular medicine. Missouri:Elsvier, Saunders. 2011:1-20.

4. Joshi P, Islam S, Pais P, Reddy S, Dorairaj P, Kazmi $\mathrm{K}$, et al. Risk factors for early myocardial infarction in South Asians compared with individuals in other countries. JAMA 2007;297(03):286-94.

5. Yusuf S, Reddy S, Ôunpuu S, Anand S. Global burden of cardiovascular diseases part I: general considerations, the epidemiologic transition, risk factors, and impact of urbanization. Circulation 2001:104(22):2746-53.

6. Islam AKMM, Majumder AAS. Coronary Artery disease in Bangladesh: A review. Indian Heart J 2013;65(04):424-35.

7. Chadha SL, Radhakrishnan S, Ramachandran K, Kaul $U$, Gopinath N. Epidemiological study of coronary heart disease in urban population of Delhi. Indian J Med Res 1990;92:424-30.

8. Enas EA, Yusuf S, Mehta JL. Prevalence of coronary artery disease in Asian Indians. Am J Cardiol 1992;70:945-9.

9. Deedwania P, Singh V. Coronary artery disease in South Asians: evolving strategies for treatment and prevention. Indian Heart J 2005;57:617-31.

10. Gupta R, Gupta VP. Meta-analysis of coronary heart disease prevalence in India. Indian Heart $\mathrm{J}$ 1996;48:241-5.

11. O'Gara PT, Kunhner FG, Ascheim DD, Casey DE Jr, Chung MK, de Lemos JA et al. 2013 ACCF/AHA Guideline for the management of st-elevation myocardial infarction: A report of the Americal College of Cardiology Foundation/American heart Association Task Force on Practice Guidelines. Circulation 2013; 127(4):e362-425.

12. Jneid $\mathrm{H}$, Anderson $\mathrm{JL}$, Wright $\mathrm{RS}$, Adams CD, Bridges CR, Casey DE Jr et al. 2012 ACCF/AHA focused update of the guidelines for the management of patients with unstable angina/non-st-elevation myocardial infarction (updating the 2007 guideline and replacing the 2011 focused update): A report of the American College of Cardiology Foundation/American College of Cardiology Foundation/American Heart Association Task Force on Practice Guidelines. J AM Coll Cardiol 2012;60(7):645-81.

13. Gupta R, Deedwania PC, Gupta A, Rastogi S, Panwar $\mathrm{RB}$, Kothari K. Prevalence of metabolic syndrome in an Indian urban population. Int J Cardiol 2004;97: 257-61.

14. Gaziano MJ, Manson JE, Ridker PM. Primary and secondary prevention of coronary heart disease. In : Libby P, Bonow RO. Mann DL, Zipes DP, editors. Braunwalds Heart disease. A text book of cardiovascular medicine. 8th ed. Saunders: Philadelphia; 2008. P. 1119-48.

15. Enas EA, Yusuf S, Mehta J. Meeting of the International Working Group on Coronary Artery Disease in South Asians. 24 March 1996, Orlando, Florida, USA. Indian Heart J 1996;48:727-32.

16. Jafary $M H$, Samad $A$, Ishaq $M$, Jawaid $S A, A$ hmad $M$, et al. Profile of Acute Myocardial Infarction (AMI) in Pakistan. Pak J Med Sci. 2007; 23:485-9.

17. Hafeez S, Javed A, Kayani AM. Clinical profile of patients presenting with acute ST elevation myocardial infarction. JPMA 2010; 60:190.

18. Boden WE, O' rouke RA. COURAGE trial group. The evolving pattern of coronary artery disease in the US and Canada: Baseline characteristics of the clinical outcomes Utilizing Revascularization and Aggressive Drug Evaluation (COURAGE) trial. Am J Cadiol. 2007; 99:208-12.

19. Islam AEMM, Faruque M, Chwodhury AW. Risk factor analysis and angiographic profiles in first 228 cases undergone coronary angiography in cardiac cath Lab in Dhaka medical college hospital. Cardivascular Journal 2011; 3(2):122-125.

20. Yusuf S, Hawken S, Ounpuu S, Dans T, Avezum A, Lanas $F$, et al. Effect of potentially modifiable risk 
factors associated with myocardialinfarction in 52 countries (the INTERHEART study): Casecontrolstudy. Lancet 2004;364:937-52.

21. Xavier D, Pais P, Devereaux PJ, Xie C, Prabhakaran D, Reddy KS, et al. Treatment and outcomes of acute coronary syndromes in India (CREATE): A prospective analysis of registry data. Lancet 2008;371:1435-42.

22. Stone PH, Muller JE, Hartwell T, York BJ, Rutherford JD, Parker CB et al. The effect of diabetes mellitus on prognosis and serial left ventricular function after acute myocardial infarction: Contributor of both coronary disease and diastolic left ventricular dysfunction to the adverse prognosis. Jam Coll Cardiol. 1989; 14:49-57.

23. Akanda MAK, Ali SY, Islam AEMM, Rahman MM, Parveen A, Kabir MK, et al. Demographic Profile, Clinical Presentation \& Angiographic Findings in 637 Patients with Coronary Heart Disease. Faridpur Medical College Journal 2011; 6(2):82-85.

24. Farmer JA, Gotto AM. Dyslipidemia and other risk factors for coronary heart disease. In: Braunwald E, editor. Heart Disease: A Textbook of Cardiovascular Medicine. 5th ed. Philadelphia: WB Saunders; 1997. p. $1126-60$.
25. Hong MK, Cho SY, Hong BK, Chang KJ, Chung IM, Lee $\mathrm{MH}$ et al. Acute myocardial infarction in young adults. Yonsei Med J. 1994; 35:184-9.

26. Siwach SB, Singh H, Sharma D, Katyal VK. Profile of young acute myocardial infarction in Harayana. J Assoc Physicians India 1998; 46:424-6.

27. Rahman A, Majumder AAS, Ali A, Shaha GK. Risk factors, Clinical and Coronary Angiographic Profile of Coronary Artery Disease in Young Bangladeshi Population. Circulation Journal 2005; 69(suppl I):10-12.

28. Khanal S, Obeidat O, Lu M, Douthat L. Dyslipidaemia in Patients with Angiographically confirmed Coronary Artery Disease- An Oppurtinity for Improvement. Clin Cardiol. 2004; 29:577-580

29. Saleheen D, Fossard P. CAD risk factors and acute myocardial infarction in Pakistan. Acute Cardiol. 2004; 59:417-24.

30. Ahmad I, Shafique Q. Myocardial infarction under age 40: Risk factor and coronary arteriographic findings. Ann King Edward Med Coll. 2003; 9:262-5.

31. Islam AKMM, Mohibullah AKM, Paul T. Cardiovascular Disease in Bangladesh: A Review. Bangladesh Heart Journal. 2016; 31(2):80-99. 